\title{
Edgar Morin e a educação integral: subsídios para essa associação
}

\author{
Edgar Morin and integral education: subsidies for this association \\ Edgar Morin y la educación integral: subvenciones para esa asociación \\ DIOVANE DE CÉSAR RESENDE RIBEIRO \\ Orcid Id: http://orcid.org/0000-0003-1507-1584 \\ Universidade Federal do Triângulo Mineiro \\ WAGNER WEY MOREIRA \\ Orcid Id: http://orcid.org/0000-0002-3705-9319 \\ Universidade Federal do Triângulo Mineiro
}

\begin{abstract}
Resumo: $\mathrm{O}$ trabalho apresentado teve como subsídio a fundamentação teórica de uma investigação desenvolvida no âmbito de um mestrado em Educação. Tivemos como objetivo, neste artigo, associar os pensamentos de Edgar Morin com a concepção de Educação Integral. A partir da revisão bibliográfica sobre os temas, entendemos a Educação Integral como aglutinadora dos pensamentos propostos pelo filósofo francês no que tange à reforma do pensamento por meio da educação.
\end{abstract}

Palavras-chave: Edgar Morin. Teoria da Complexidade. Educação Integral.

Abstract: The presented work had as a background the theoretical foundation of a research developed at the level of a Master's in Education. In this article, we aimed to associate Edgar Morin's thoughts with the concept of Integral Education. From the bibliographic review on the themes, we understand Integral Education as an aggregator of the thoughts proposed by the French philosopher concerning the reform of thought through education.

Keywords: Edgar Morin. Complexity Theory. Integral Education.

Resumen: El trabajo presentado tuvo como subsidio los fundamentos teóricos de una investigación desarrollada a nivel de una Maestría en Educación. En este artículo, buscamos asociar los pensamientos de Edgar Morin con el concepto de Educación Integral. De la revisión bibliográfica sobre los temas, entendemos la Educación Integral como una aglutinación de los pensamientos propuestos por el filósofo francés con respecto a la reforma del pensamiento a través de la educación.

Palabras clave: Edgar Morin. Teoría de la Complejidad. Educación Integral. 


\section{INTRODUÇÃO}

As legislações e políticas públicas educacionais apresentam em seu escopo a Educação Integral como uma concepção da Educação. Recentemente, contamos com a Base Nacional Comum Curricular, homologada em 2018, trazendo no seu texto introdutório a proposta de construção de um currículo destinado ao desenvolvimento integral dos alunos da Educação Básica. O próprio documento concebe a Educação Integral para além do reducionismo intelectual e afetivo. Considera as pluralidades existentes na formação dos alunos e os entende como seres subjetivos e ao mesmo tempo imersos em uma cultura/comunidade/ sociedade (BRASIL, 2018).

Autores como Moll (2012, 2009), Arroyo (2012), Gadotti (2009), Cavaliere (2007, 2002) e Guará (2006) figuram no cenário educacional brasileiro como referências para o desenvolvimento de ações que tenham a formação integral como concepção norteadora do trabalho educativo. Esses autores propõem ações plurais e conectivas, por meio de um diálogo entre os espaços, tempos e agentes educativos dos territórios em que o ambiente escolar está localizado.

A instituição de ensino é concebida como articuladora de um trabalho educacional, mas não como o único ambiente formador existente na cidade. Há outros espaços, tempos e atores constituintes desse processo. Defendem a constituição de uma comunidade educativa, imbuída de objetivos formadores dos seus habitantes, sendo eles educandos e ao mesmo tempo corresponsáveis pelo trabalho educativo dos seus semelhantes.

Gadotti (2009), apresenta em seu trabalho a conectividade, a intersetorialidade, a intertransculturalidade, a intertransdiciplinaridade, a sustentabilidade e a informalidade como princípios orientadores para ações que visem à Educação Integral como elementos fundamentais para a concepção das políticas públicas em vigência no âmbito nacional.

Partindo do entendimento sobre a importância de se educar integralmente, buscamos as contribuições do filósofo da complexidade, Edgar Morin, para responder aos anseios e às demandas da atualidade, em um cenário incerto, enfatizando a necessidade de educar para a compreensão de si e do outro em busca de estabelecer uma identidade planetária na sociedade-mundo em que vivemos.

Enquanto sociedade do conhecimento e, ao mesmo tempo, Terrapátria, o planeta urge por mudanças cruciais para a manutenção das condições básicas de existência da vida humana. Ao mesmo tempo, as evoluções biológicas e os desenvolvimentos filosóficos e pedagógicos apontam para se pensar em uma educação contextualizada, complexa, inter-multi-transdisciplinar, inter- 
transcultural e compartilhada entre diferentes atores e setores da sociedade. No entanto, fica a questão: quais as necessidades de nosso tempo? Os valores humanos são cada vez mais enfatizados na formação dos educandos para se humanizar as relações e, ao mesmo tempo, sensibilizar pelos múltiplos interesses de uma sociedade adoecida e, ainda, cega para os destinos incertos apontados pelo futuro (MORIN, 2011).

A Educação Integral, hoje, não é mais um projeto de movimento: é uma concepção de educação garantida pelas legislações, no currículo, nas relações e na proposta pedagógica das escolas e dos sistemas de ensino.

Falar de Educação Integral requer compreender a sociedade como um todo, pois a escola faz parte deste complexo chamado Terra. Educar Integralmente está além da exclusividade de atender às demandas econômicas. A concepção de educação defendida poreste trabalho pressupõe o desenvolvimento das capacidades humanas em uma perspectiva ecológica, planetarizada, complexa, em que os interesses dos seres humanos, seus valores para o pensar bem (MORIN, 2017), estejam acima da competividade, do lucro e da formação única e exclusivamente para a atuação profissional. É preciso, conforme destaca Morin (2012), educar para as certezas e as incertezas da vida, compreensão e solidariedade, a partir de atitudes éticas consigo, com o próximo e com o cosmo (incluindo nossa TerraPátria). As influências sociais, históricas e biológicas nos acompanham desde o surgimento do Universo, e devemos considerar o caminho incerto do trajeto percorrido por nós. O rompimento com o divisionismo instaurado entre a tríade indivíduo/sociedade/espécie pode ser superado pela proposição do pensamento complexo, conforme defende o filósofo francês.

Enquanto indivíduos, carregamos em nós as singularidades e as aproximações biológicas e culturais dos seres humanos; somos criados e criadores das organizações sociais e dos agrupamentos comunitários e pertencemos à espécie Homo Sapiens, evoluída e dotada de razão e loucura. Não somos a divisão dessa tríade, mas a integração e a interlocução dela. Somos seres complexos, produtores e produtos de uma complexidade.

Este artigo foi elaborado a partir da fundamentação teórica de uma investigação de mestrado do Programa de Pós-Graduação em Educação, na qual associamos a Teoria da Complexidade com a Educação Integral. Nesta produção pretendemos apresentar as reflexões sobre os estudos promovidos entre as aproximações das duas temáticas, no que tange especialmente ao desenvolvimento integral do ser humano para se alcançar a reforma do pensamento por meio da educação. 


\section{PENSAMENTO COMPLEXO E A EDUCAÇÃO INTEGRAL: CONTRIBUIÇÕES FILOSÓFICAS}

A formação do ser humano continua ativa na agenda dos projetos e das políticas públicas educacionais, para se atender aos interesses das classes dominantes e dominadas. $\mathrm{Na}$ atual conjuntura de uma sociedade neoliberal, ocidentalizada e com fortes traços mercadológicos em nosso cotidiano, tentamos responder à seguinte questão: por que educar integralmente?

As ciências da modernidade influenciaram o modelo educacional existente (MORIN, 2011). A tentativa de se compreender os sujeitos e objetos a partir de especializações na expectativa de encontrar respostas deterministas, influenciou o modelo de ensino fragmentado das disciplinas e a disjunção entre as ciências. Morin (2012), no entanto, nos apresenta o óbvio: o funcionamento indissociável da sociedade, do indivíduo e da espécie. A solidariedade, ora tida apenas como valores cultivados pelo espírito (aqui tratamos como mente) se apresenta também desde a organização cósmica, passa pela simbiose celular e se faz presenta na espécie e no indivíduo que nos tornamos.

Os atos solidários referidos pelo teórico francês podem ser identificados nas trocas de informações entre as células corporais; a relação de auxílio, produção e transmissão de conhecimentos entre os povos, gerações e indivíduos, podendo influenciar na transformação ou permanência dos ritos, símbolos e organizações comunitárias. Amiúde deveríamos estar em trocas solidárias e, na perspectiva da Educação Integral, a valorização e o fomento das capacidades humanas, sem sobreposição, e a incorporação de valores e saberes culturais são princípios fundamentais para o desenvolvimento do indivíduo. Aprendemos e ensinamos, formamos e estamos em formação pelos contatos estabelecidos entre o en e nós.

A fragmentação não cabe no desenvolvimento do ser humano. Mesmo com a negação da integração interdependente de todos os fatores, estamos em conexão conosco, com o outro e com a organização planetária. A cooperação é viva e presente em nosso cotidiano. No entanto, para Morin (2012), ainda estamos na segunda pré-história da humanidade, por não termos todas as nossas potencialidades amplamente desenvolvidas, e permanecemos na Idade de Ferro, pela importância dada por nós às forças bélicas, imperiosas nas sociedades, e pelas relações entre os pares serem esvaziadas de harmonia e solidariedade.

A neurociência comprovou o quão pouco utilizamos de nossas capacidades cerebrais diante de toda a potencialidade do Sistema Nervoso Central (MORIN, 2012). Mesmo nos destacando diante da natureza pelas nossas faculdades superiores desenvolvidas em comparação aos outros animais, estacionamos em uma era na qual a subjugação, incompreensão, racionalidade, autojustificação e 
a disjunção dos saberes impedem a consolidação de um planeta interconectado pelas redes físicas e pelos sentimentos fraternos e de pertença a esse orbe. Ainda em seu trabalho, com o propósito de nos mostrar o quanto precisamos nos reaproximar de nossa humanidade, daquilo que nos torna humanos, o filósofo nos aguça a pensar sobre o porvir de nossa espécie:

\footnotetext{
Poderemos assumir o destino dialógico sapiens-demens, ou seja, manter a razão sem ficar encerrados nela, conserva a loucura sem cair nela?

Poderemos suportar a situação neurótica do ser humano no mundo, consciente, ao mesmo tempo, de ser tudo para si mesmo e nada no universo?

Poderemos assumir a angústia do inacabamento de nossas vidas e da incerteza do destino humano? Poderemos aceitar ser abandonados pelos deuses? Poderemos abandoná-los?

Saberemos que somente o amor e a poesia vividos são respostas capazes de levar a enfrentar angústia e mortalidade?

Poderemos inibir a megalomania humana e regenerar o humanismo?

Poderemos fortalecer o mais precioso, o mais frágil, essas últimas emergências que são o amor e amizade?

Poderemos praticar a reforma interior que nos tornaria melhores?

Poderemos, um dia, "habitar poeticamente a Terra"?

A humanidade está em formação. Há possibilidades de rechaçar a barbárie e realmente civilizar os humanos?

Será possível transformar a hominização em humanização?

Será possível salvar a humanidade, realizando-a?

Nada está definido, nem o pior (MORIN, 2012, p.295).
}

Impulsionamo-nos para a automatização de nossas ações e relegamos o desenvolvimento de nossa humanidade, como valores pertinentes ao "ser" humanos, para segundo plano.

Porém, Morin (2017) apresenta caminhos para um contexto pelo pensar bem, mantendo a relação ecológica e indissociável entre indivíduo/sociedade/ espécie por meio do pensamento complexo. Em uma definição simples, mas não simplificada, poderíamos conceituar a complexidade como o todo das partes e a parte do todo, tessituras em conjunto. Há nos trabalhos do filósofo a proposição de reformas interdependentes para a aproximação entre ciências, indivíduos, culturas, sociedades e Estados-nação, imbuídos de propósitos comuns, mesmo mantendo suas singularidades (MORIN, 2015, 2013, 2003). Acredita que as reformas da vida, sociedade e pensamento contribuem para a ruptura do paradigma compartimentalizado existente na contemporaneidade. A reforma do pensamento, por sua vez, se dará pela educação, sendo ela responsável pela formação dos seres humanos. 
Chegamos então na importância de se pensar a educação não como salvadora, mas parte do processo de reforma do planeta. Sendo o pensamento complexo o resultado do todo presente nas partes e as partes integrando o todo, a concepção de Educação Integral, defendida neste trabalho, corrobora com a afirmação da Guará (2006), quando ela considera o desenvolvimento das capacidades biológicas, sociais, afetivas, cognitivas, éticas, lúdicas e estéticas do indivíduo, sem sobreposição entre elas, porém integradas. Ao mesmo tempo contrapomos a ideia de uma educação plena, completa, quando, pela própria posição do Morin (2017), somos seres inacabados e desconhecemos as potencialidades cerebrais, espirituais e corporais de nossa espécie. Por isso, para nós, Educação Integral pode ser entendida como o desenvolvimento das potencialidades humanas, no fomento e na integração das capacidades, aceitando o nosso inacabamento, mas atuando, mesmo na incerteza do porvir, na promoção das possibilidades atuais e futuras de nossa evolução enquanto espécie e seres humanos.

Os escritos de Morin (2017, 2013, 2012, 2011a, 2011b, 2003) foram o princípio filosófico para o desenvolvimento do nosso trabalho, as respostas emergentes para se educar integralmente na sociedade atual, considerando que os caminhos entre a separação e a integração dos saberes, seres e ambientes, se encontram em relação ténue e incerta. A complexidade é apresentada como resposta para se romper com o modelo fragmentado de sociedade e educação, propondo a aproximação entre os conhecimentos e concebendo o ser humano como inteiro, em seus aspectos biológicos, físicos, sociais, históricos e cósmicos.

A fragmentação, a especialização das ciências, o rompimento entre o sujeito e o objeto banalizam tudo o quanto possa tornar o ser humano sensível e próximo da sensibilidade humana. Exclui da produção do conhecimento o espírito, o qual é dotado de toda a poesia, para enfatizar a racionalização do ser e (sobre)viver em sociedade. Anula-se a essência da humanidade e a enclausura em leis concebidas como deterministas para o funcionamento dessa sociedade. $\mathrm{Na}$ perspectiva de Santos (2008), as ciências modernas pretendem dominar a natureza pelo mapeamento de suas leis, por meio da redução e quantificação dos resultados obtidos durante as pesquisas. Ao determinarem a causa e o fim, os cientistas acreditavam compreender o funcionamento de tudo, prevendo seus acontecimentos.

Com o apogeu do positivismo, tentaram imprimir os determinismos nas ciências humanas e sociais, com o intuito de mapear o funcionamento da sociedade, do indivíduo e da espécie, regulando os acontecimentos e interferindo neles por meio dos padrões identificados ao longo das pesquisas, ou seja: subjugá-los a partir das descobertas e reproduzi-las na sociedade. No entanto, 
a subjetividade do ser humano, as metamorfoses biológicas, históricas e sociais impedem a proliferação de ideias deterministas como se fosse possível empregar leis gerenciadoras dos acontecimentos sociais, antropológicos, filosóficos, relacionais e humanos (SANTOS, 2008).

A fragmentação da pesquisa disciplinar impede a contextualização, isolando os cientistas em sua especialidade sem que estes tenham condições de abarcar outros aspectos capazes de dar completude às respostas para diferentes questões, pois "Os problemas são interdependentes no tempo e no espaço, enquanto as pesquisas disciplinares isolam os problemas uns dos outros" (MORIN, 2011a, p.51).

Ao estabelecer hiperespecializações para se atender a fins específicos, o pensamento moderno influenciou na separação dos conhecimentos e, consequentemente, como eles seriam transmitidos. A organização escolar tem reproduzido o modelo proposto por Descartes, talvez não de maneira consciente, quando se considera os imprintings do neoliberalismo no campo educacional. Os professores, formados nessa perspectiva, apenas reproduzem as características de sua formação enquanto docentes e, por que não, enquanto seres humanos.

A partir da crise da modernidade, a qual percebe a incapacidade de se responder às questões científicas, filosóficas e sociais com base nos determinismos, emerge um novo paradigma de aproximação entre as ciências da natureza e as ciências sociais/humanas. O dualismo começa a ser superado no campo científico e a transdisciplinaridade propõe a aproximação entre as áreas do saber para se compreender as questões filosóficas, sociais, naturais e morais (MORIN, 2015). O conhecimento passa a ser concebido em esfera local e global, pelo vasto campo a ser explorado e, ao mesmo tempo, apropriado pelos seres humanos. Ao contrário da rigorosidade, exclusão e segregação das ciências modernas, a atualidade propõe a inclusão, integração e criatividade do pesquisador na produção do conhecimento (SANTOS, 2008).

A contemporaneidade clama pela aproximação das áreas, fomentando trabalhos intertransdisciplinares para se responder às demandas atuais, em que a contextualização do conhecimento é necessária para continuar com o progresso mundial.

A era planetária necessita situar tudo no contexto planetário. O conhecimento do mundo como mundo se transforma em necessidade simultaneamente intelectual e vital. Trata-se do problema universal de todo cidadão: como conseguir acesso às informações sobre o mundo e como ter a possibilidade de articulá-las e de organizá-las. Contudo, para articulá-las e organizá-las, e com isso reconhecer e conhecer os problemas do mundo, é necessária uma reforma do pensamento. Essa reforma, que inclui o desenvolvimento da contextualização do conhecimento, exige ipso facto a complexificação do conhecimento (MORIN, 2011a, p.50). 
Para o filósofo, a Terra passa pela planetarização, quando as sociedades, ainda na era moderna, começam a se aproximar por meio das trocas e integrações marítimas, biológicas (reprodução e transmissão de doenças), culturais, sociais e individuais (miscigenação). Estamos em um movimento intertranscultural, no qual as culturas promovem a troca de conhecimentos e incorporam outros elementos às suas realidades.

Unidos pelo propósito de manutenção do planeta e diante das incertezas do futuro, somos convidados a repensar e aproximarmo-nos uns dos outros, de maneira solidária, ética e compreensiva, para se emergir uma sociedade de pensamento e ações complexas.

A mundialização permitiu - por meio das tecnologias da informação e comunicação, meios de locomoção aéreos, terrestres e marítimos - o diálogo entre povos, sociedades e etnias. As manifestações artísticas e culturais extrapolaram as fronteiras territoriais, alcançando localidades onde foram apresentadas, incorporadas ou reinventadas. As relações sociais, proporcionadas pela mundialização, resultaram em um ambiente favorável para se instaurar uma sociedade-mundo, transcendendo as barreiras terrestres e virtuais, aproximando os povos com conhecimentos distintos, agora, podendo ser compartilhados entre todos. Comungamos de princípios humanos semelhantes e, ao mesmo tempo, nos diferenciamos quanto aos modelos de vida, de sociedade, cultura e individualidade (MORIN, 2017).

Constituímos nossa humanidade pelas relações com nossos pares, por meio da apropriação de conhecimento e pelas experiências, construindo valores, crenças, hábitos e saberes. Na filosofia africana, há um termo muito comum utilizado pelos povos do continente mãe. A expressão Ubuntu: eu sou porque nós somos, carrega para nós a máxima sintetizadora da importância das nossas "humanidades" para a constituição de outras "humanidades" e da "humanidade" da Terra-Pátria. A expressão derivada da língua bantu, não tendo tradução para o português,

[...] pode, entretanto, ser traduzido para significar que ser um humano é afirmar sua humanidade por reconhecimento da humanidade de outros e, sobre estas bases, estabelecer relações humanas com os outros. Ubuntu, entendido como ser humano (humanidade); um humano, respeitável e de atitudes cortesas para com outros constitui o significado principal deste aforismo. Ubu-ntu, então, não apenas descreve uma condição de ser, na medida em que é indissoluvelmente ligado ao umuntu, mas também é o reconhecimento do vir a ser e não, como desejamos enfatizar, o ser e o vir a ser (RAMOSE, 1999, p.3). 
Ramose (1999) também reforça a concepção do ser humano em sua totalidade, a partir da filosofia Ubuntu. A humanidade do eu é construída pelas relações estabelecidas com a bumanidade do outro, proporcionando a construção do que sou e posso vir a ser. Morin (2012) enfatiza a importância de retornarmos ao primitivismo de nossa humanidade, não nas condições das espécies, mas pela sensibilidade e poesia de saber viver e pensar bem. Na maioria das vezes, nos tornamos seres reprodutores de dogmas, mitos e símbolos sem termos consciência das produções e propagações dessas ideias. O autor caracteriza esse fenômeno como "despertos e sonâmbulos"

\begin{abstract}
No meio de um universo estranho que nos é tão familiar, somos autômatos, sonâmbulos, possuídos. Praticamos alucinadamente a nossa profissão de viver, como se fôssemos, realmente, autômatos programados desde sempre, com nosso coração que bate maquinalmente a cada segundo, nosso organismo que trabalha hiperciberneticamente com seus órgãos e miríades de células, nosso enorme computador cerebral cujas operações inconscientes mantêm nossa consciência à mercê dele. Somos habitados pela vida, pela espécie, por nossos ascendentes, pela cultural, pela sociedade, pelas ideais. Sofremos imprinting, submetemnos ao paradigma, à lei. Somos máquinas que parecem, muitas vezes, triviais. Mas também somos máquinas de recalcar, esquecer, ocultar, iludir, mitificar, enganarmo-nos (MORIN, 2012, p.285).
\end{abstract}

Mesmo como seres despertos e sonâmbulos, nossa formação não acontece de maneira isolada. Por meio das relações sociais, constituímos o nosso en, a nossa identidade e a identidade do planeta. Somos resultados de todo o histórico e evoluções do cosmo e de nossos ancestrais. Somos seres humanos porque nos reconhecemos enquanto tal e reconhecemos nossos semelhantes como iguais. Somos cidadãos porque reconhecemos uns aos outros como detentores de direitos e deveres nas sociedades e, por que não, no mundo.

\title{
EDUCAÇÃO INTEGRAL E O HOMO COMPLEXUS: OS SABERES NECESSÁRIOS PARA O SEU DESENVOLVIMENTO
}

Partindo do princípio de conectividade/aproximação entre os conhecimentos, culturas, sociedades e valorização da história planetária, Morin (2011b) apresenta, de maneira objetiva, reflexões sobre a educação, apontando considerações quanto a formação dos cidadãos terrestres da nova era. Sempre sobre a lógica da incerteza, aposta e esperança, o autor resume em tópicos o pensamento complexo para a reforma da educação. Não temos a intenção de reproduzir os escritos do autor, no entanto, consideramos pertinente, para 
a construção deste trabalho, repassá-los e, de maneira sintética, comentá-los e associá-los ao que acreditamos deva ser a concepção de todas as escolas, sistemas e políticas educacionais no Brasil: educar integralmente.

A Educação Integral, enquanto concepção, apresenta princípios interlocutores com as ideias defendidas pelo filósofo. A contextualização do conhecimento, a união entre espírito e matéria, assertivas sobre a sociedade enquanto ambiente de relações humanas entre os cidadãos terrestres, a produção e reprodução de conhecimentos, a incerteza do futuro, bem como a educação para a solidariedade, compreensão, ética e para viver poeticamente, encontramse imbricadas nos discursos de autores brasileiros atuantes na defesa por uma concepção e prática de Educação Integral.

A fragmentação da pesquisa e, consequentemente do conhecimento, liberou o divisionismo existente nas propostas curriculares e práticas pedagógicas no cenário educacional atual, no qual não há intercomunicação entre saberes, setores, atores e o exercício profissional docente. A superação desse contexto se torna imperiosa para a concretização de qualquer política destinada à Educação Integral.

Ao se tratar da transcendência deste divisionismo, Morin (2011b) retrata sobre as consequências de não preparar o ser humano para aprender a conhecer, destacando:

É impressionante que a educação que visa a transmitir conhecimentos seja cega quanto ao que é o conhecimento humano, seus dispositivos, suas enfermidades, suas dificuldades e tendências ao erro e à ilusão, e não se preocupem em fazer conhecer o que é conhecer. [...] Trata-se de armar cada mente para o combate vital rumo a lucidez (p.15).

Em outras palavras, trata-se de preparar o ser humano para as incertezas do futuro, sabendo das mudanças em relação aos saberes/conhecimentos, os quais são significados e ressignificados pela própria humanidade. Nenhum conhecimento está pronto e acabado e tampouco será eterno ou imutável (MORIN, 2013). Temos exemplos de teorias refutadas no passado e, hoje, comprovadas como verdadeiras, assim como o inverso. A ilusão, no entanto, impede de vislumbrar a mutabilidade e as inúmeras possibilidades de ampliar os diferentes campos intelectivos quanto as verdades e erros em relação ao mundo e ao cosmo. Antes, considerávamos a Terra como centro do Universo, hoje comprovamos uma outra realidade, inversa aos conhecimentos antigos sobre astronomia. Para tanto 
Devemos compreender que existem condições bioantropológicas (as aptidões do cérebro/mente humana), as condições socioculturais (a cultura aberta, que permite diálogos e trocas de ideias) e condições noológicas (as teorias abertas), que permitem "verdadeiras" interrogações, isto é, interrogações fundamentais sobre o mundo, sobre o homem e sobre o conhecimento. Devemos compreender que, na busca da verdade, as atividades auto-observadoras devem ser inseparáveis das atividades observadoras, inseparáveis das críticas, os processos reflexivos, inseparáveis dos processos de objetivação (MORIN, 2011b, p.29).

A solidariedade se faz presente na construção do conhecimento. Educar para a possibilidade dos erros e das ilusões, não as concebendo como verdades absolutas, mas enquanto condição de seres falíveis que somos. Estamos em processos de descobertas e redescobertas sobre as origens do próprio universo, da vida terrestre e das potencialidades de nossa espécie. Entender este emaranhado presume as possibilidades de erros. Ao se pensar na concepção de Educação Integral, devemos preparar nossas crianças e nossos jovens para o futuro incerto e, ao mesmo tempo, educá-los para persistirem em tentativas sem frustrações diante de erros. Os erros são tentativas, de acordo com os conhecimentos utilizados por cada ser humano para subsidiar suas escolhas. As escolhas são frutos das possibilidades de liberdade, quando também temos disponibilizadas condições para as exercemos.

A contextualização do conhecimento também figura como um dos saberes defendidos pelo filósofo da complexidade, pois ela é o próprio pensamento complexo (MORIN, 2013). Para ele

A supremacia do conhecimento fragmentado, de acordo com as disciplinas impede frequentemente que se opere o vínculo entre as partes e a totalidade e deve ser substituída por um modo de conhecimento capaz de apreender os objetos em seu contexto, sua complexidade, seu conjunto (MORIN, 2011b, p.16).

O autor defende uma perspectiva global do conhecimento, do saber, da sociedade. Tanto enquanto humanos ou sociedade, somos multidimensionais, influenciados pelos meios e pelas relações. Não há como utilizarmos separadamente cada uma das nossas capacidades: intelectual, física, ética, estética, social, afetiva, lúdica e biológica, pois não há sobreposição ou justaposição entre elas. Carregamos traços culturais das organizações sociais, do nosso passado. As alterações genéticas advêm de adaptações culturais em diferentes ambientes naturais. A identidade se constrói a partir das nossas relações com o mundo e tudo produzido pelos grupos: cultura, saber e conhecimento, pois “" [...] a sociedade, como um todo, está presente em cada indivíduo, na sua linguagem, em seu saber, em suas obrigações e em suas normas" (MORIN, 2011b, p.35). 
Os educandos carregam seus traços, sua identidade cultural a partir das construções e apropriações realizadas por eles ao longo de suas experiências com e pelo planeta Terra. São seres complexos, integrais, assim como os professores, iguais protagonistas desse processo, também o são.

Podemos aprender de diferentes maneiras a partir de contextos distintos. Temos condições de estabelecer conexões entres conhecimentos e superar a proposta cartesiana de disciplinar o saber.

A educação deve favorecer a aptidão natural da mente em formular e resolver problemas essenciais e, de forma correlata, estimular o uso da inteligência geral. Este uso total pede o livre exercício da curiosidade, a faculdade mais expandida e a mais viva durante a infância e a adolescência, que, com frequência, a instrução extingue e que, ao contrário, se trata de estimular ou, caso esteja adormecida, de despertar (MORIN, 2011b, p.37).

A educação deve considerar outros aspectos do ser humano para além da memorização e reprodução de conhecimentos (capacidade intelectiva). É necessária a formação de professores e alunos pesquisadores, seres com ânsia de novas descobertas, motivados com a sua curiosidade em estabelecer conexões entre o todo com as partes e vice-versa.

Naperspectiva da Educação Integral, a superação da compartimentalização dos conhecimentos é via indispensável para a reforma do pensamento e desenvolvimento integral dos educandos. São necessárias, nesse sentido, a construção de propostas pedagógicas integradoras dos sujeitos, dos saberes, tempos, espaços e contextos e integradas à realidade (GADOTTI, 2009), às necessidades dos sujeitos envolvidos no processo educativo, ao mundo e sua complexidade.

Como dissemos, a humanidade do outro contribui para a constituição do eu humano. Nossas relações promovem a integração de saberes e, ao mesmo tempo, evidenciam o que nos torna uno e diverso dentro de um contexto social, local ou mesmo planetário. Somos a soma do local e global, uno e multidimensional, identidade e diversidade.

A sensibilidade, outrora presente no cotidiano da antiguidade, se esvaiu pela globalização ocidental do quadrimotor do planeta: economia, indústria, ciência e lucro (MORIN, 2017). Quanto mais triviais em nossos atos, mecânicos em nossas ações e possuídos pelas ideias criadas e elas possuídas por nós, estaremos na contramão dessa marcha.

Para o autor, a religação da humanidade com a sua humanidade acontecerá por vias poéticas, quando nos permitirmos a apreciar o mundo e suas maravilhas. Isso resulta no saber viver. 
Se definimos o ser humano somente pela noção de homo sapiens, a afetividade aparece como supérflua, parasita, perturbadora. A loucura e o delírio aprecem como carências patológicas que alteram o fundo racional sadio da natureza humana. A sabedoria identifica-se então como prudência, como arte de viver pela qual a razão governa dominando ou eliminando as paixões, ideia, difundida durante muito tempo, de que o exercício da razão elimina por si mesmo a afetividade.

Sabemos agora que todas as atividades racionais da mente são acompanhadas de afetividade. Esta que, certo, pode imobilizar a razão é a única capaz de mobilizála.

A partir disso, a ideia de sabedoria complexifica-se: não elimina mais a afetividade, mas a integra. Sabemos que a paixão pode cegar, mas também que ela pode iluminar a razão se esta reciprocamente a ilumina. Precisamos de inteligência racional, mas também de afetividade, simpatia, compaixão. [...] a qualidade de vida comporta emoção, paixão, gozo. [...] Não existe fronteira clara entre racionalidade e delírio, pois a afetividade os envolve (MORIN, 2012, p.137).

A capacidade estética, nem sobreposta e nem justaposta, é caminho para o desenvolvimento da poesia pelo viver. Há, de fato, espaços, tempos e atores na promoção e no fomento desse saber viver poeticamente. Estamos longe de atingir a perfeição de nosso ser, mas a vida poética nos permite acessar capacidades, talvez adormecidas, e capazes de tornar nosso olhar mais sensível para nós e o outro.

Na perspectiva da Educação Integral, encontramos no ensino da arte e cultura meios de acesso à poeticidade do viver, assim como na prática de esportes ou acesso às tecnologias. Qualquer uma dessas áreas nos permite desfrutar de momentos sensíveis e de conexão com o conhecimento, autoconhecimento, com a história, com o outro e nos desperta a sensibilidade e o prazer pelo saber viver.

Pertencemos ao mesmo grupo social terrestre. Mesmo em nossas individualidades, há semelhanças de ordem física, biológica, social, afetiva, ética, estética, lúdica, física e intelectual. Somos, ao mesmo tempo uno e diversos. As semelhanças e diferenças têm origem a partir das construções, reflexões, conhecimentos e produções derivados de nossa humanidade. Construímos nossas identidades - individuais e coletivas -, por meio dos intercâmbios (dar e receber) humanos estabelecidos entre nós (MORIN, 2011).

Para além de compreender o educando enquanto aprendiz e o professor enquanto profissional, a Educação Integral deve pautar-se nas humanidades existentes em cada um e os seus encontros, possibilitando a integração de saberes, práticas, crenças, valores, dogmas, hábitos, organização social, cultura, arte e outras especificidades que nos assemelham e diferem, o uno e o diverso. Compreende-se a possibilidade de educar integralmente para além dos muros, currículos e profissionais escolares. É preciso educar pela/pelas humanidade/ humanidades existentes no âmbito local e global. 
Em busca dessa humanidade, precisamos considerar o humano em sua complexidade. Diferente da visão cartesiana, Morin (2011b) considera o ser humano em contexto complexo e bipolarizado.

O homem da racionalidade é também o da afetividade, do mito e do delírio (demens). O homem do trabalho é também o homem do jogo (ludens). O homem empírico é também o homem do imaginário (imaginarius). O homem da economia é também o do consumismo (consumans). O homem prosaico é também o da poesia, isto é, do fervor, da participação, do amor, do êxtase. O amor é poesia. Um amor nascente inunda o mundo de poesia, um amor duradouro irriga de poesia a vida cotidiana; o fim de um amor devolve-nos à prosa. Assim, o ser humano não vive só de racionalidade e de técnica; ele desgasta-se, entrega-se, dedica-se a danças, transes, mitos, magias, ritos; crê nas virtudes do sacrifício, viveu frequentemente para preparar sua outra vida além da morte (MORIN, 2011b, p.52).

Em sua multidimensionalidade, o ser humano busca o equilíbrio entre as suas polaridades. A complexidade humana nos faz pensar na educação para sua integralidade. O ser humano é integral e, por isso, já justificaria uma educação para sua formação.

A mundialização permitiu a interação e integração entre as diversas manifestações e concepções de vida, de ser humano e de mundo. Como efeito, estamos cada vez mais próximos, seja fisicamente ou virtualmente, conectados no ciberespaço ou pelas relações presenciais, possibilitando a ampliação de horizontes e visões quanto ao mundo. Somos seres humanos singulares, constituídos por outras partes graças às relações estabelecidas entre os pares.

A construção de uma consciência harmônica entre os seres humanos impede de se apertar o "botão" vermelho da destruição. Somos indivíduos terrestres e por meio das nossas relações e históricos - entre erros, tentativas e acertos - construímos a bagagem cultural e social necessária para, quando preciso, repensar os caminhos diferentes dos anteriores e que tiveram como consequências guerras de destruição em massa. Aprendemos com o passado a traçarmos um presente e futuro diferentes. Com isso, adquirimos experiências a partir das escolhas certas ou equivocadas, alcançando a sabedoria.

Para além da memorização de informações, é preciso educar para se fazer bom uso dos pilares estruturantes do conhecimento, construídos pelos antepassados. Pensar bem: utilizar os conhecimentos, saberes sem o divisionismo, mas pela integração entre eles. Por uma Educação Integral, é preciso formar crianças, jovens e adultos com consciência da importância de se planejar e projetar uma sociedade-mundo para todos, por todos, com todos e pelas mãos dos cidadãos terrestres. 
O filósofo francês convida-nos a pensar sobre a consciência e identidade terrena. Para ele, somos constituídos por muitas identidades e compartilhamos das mesmas angústias, problemas e, por que não, soluções para as crises planetária. Precisamos

Civilizar e solidarizar a Terra, transformar a espécie humana em verdadeira humanidade torna-se objetivo fundamental e global de toda educação que aspira não apenas ao progresso, mas à sobrevida da humanidade. A consciência de nossa humanidade, nesta era planetária, deveria conduzir-nos à solidariedade $\mathrm{e}$ à comiseração recíproca, de indivíduo para indivíduo, de todos para todos. A educação do futuro deverá ensinar a ética da compreensão planetária (MORIN, 2011, p.68).

Para Morin (2017), como carregamos em nossa humanidade as razões e loucuras do homo sapiens-demens, devemos pautar nossas ações por uma ética contra a barbárie interior e exterior. A ética da compreensão se dá pela autoética (conhecimento, análise, compreensão de si e do outro), socioética (responsabilidade e solidariedade na e entre as comunidades e sociedades) e antropoética (decisão individual por meio da autoética expandindo-a para o reencontro da humanidade com a humanidade esquecida pelo tempo, quando nos automatizamos no mundo). Ainda sobre a antropoética o autor nos convida a: a) assumir a condição humana complexa do ser e a relação entre indivíduo-espécie-sociedade; b) alcançar a humanidade em nós e em nossas consciências; c) assumir o destino da humanidade. Com isso, devemos

- trabalhar para a humanização da humanidade;

- efetuar a dupla pilotagem do planeta: obedecer à vida, guiar a vida;

- alcançar a unidade planetária da diversidade;

- respeitar no outro, ao mesmo tempo, a diferença e a identidade quanto a si mesmo;

- desenvolver a ética da solidariedade;

- desenvolver a ética da compreensão;

- ensinar a ética do gênero humano (MORIN, 2011b, p.94).

Educar integralmente, para além da multidimensionalidade do sujeito, é também considerá-lo enquanto humano pelas relações com seus pares, construindo sua identidade terrena e contribuindo para a consciência planetária. A vida e o aprendizado devem alçar objetivos maiores, formando seres com valores humanos, enxergando o seu próximo como coabitante do mesmo orbe e corresponsável pelo destino dele. Devemos educar a partir da vida. O humano existente no eu encontra sentido no humano do outro, por meio dos encontros e desencontros estabelecidos ao longo das vivências na sociedade-mundo. 
Enveredando nessa percepção, deve-se compreender outros espaços, tempos e sujeitos como formadores, educadores e responsáveis pela formação das gerações atuais e futuras.

Sugerimos tecer uma educação para os educandos aprenderem a conviver entre certezas e incertezas futuras, preparando-os para o porvir, sabendo da existência de riscos. "O pensamento deve, pois, amar-se e aguerrir-se para enfrentar a incerteza. Tudo que comporta oportunidade comporta risco [...]" (MORIN, 2011b, p.80). Isso também compete ao ser humano: planejar e desenvolver frente ao incerto. Compreender as fraquezas e possibilidades humanas também compete à educação.

Dentre o trabalho com a multidimensionalidade dos seres, é preciso atuar pela compreensão humana, aprendendo a compreender a si e ao outro. Morin (2011b, p.81), salienta:

Educar para compreender matemática ou outra disciplina é uma coisa; educar para compreensão humana é outra. Nela se encontra a missão propriamente espiritual da educação: ensinar a compreensão entre as pessoas como condição e garantia da solidariedade intelectual e moral da humanidade.

O autor define duas formas de compreensão: a intelectual e a humana. A primeira significa “[...] aprender em conjunto [...]” (2011, p.82). A segunda, propõe a compreensão da objetividade, subjetividade e intersubjetividade do outro. Compreender os contextos de suas escolhas, razões, atitudes e a importância do perdão (pagar o mal com o bem).

Esta comporta um conhecimento de sujeito a sujeito. [...] O outro não apenas é percebido objetivamente, é percebido como outro sujeito com o qual nos identificamos e que identificamos conosco, o ego alter que se torna alter ego. Compreender aqui, inclui, necessariamente, um processo de empatia, de identificação e de projeção. Sempre intersubjetiva, a compreensão pede abertura, simpatia e generosidade (MORIN, 2011, p.82).

Há de se considerar o outro, o humano, como ser histórico e com experiências para além do momento de fúria, por exemplo. Exige entendê-lo em sua completude, complexidade, em sua integralidade. Não há como compreender o outro se não promovo a minha introspecção, pois "O autoexame crítico permite que nos descentremos em relação a nós mesmos, por conseguinte, que reconheçamos e julguemos nosso egocentrismo” (MORIN, 2011b, p.87).

A compreensão também se estende às sociedades, por meio das relações estabelecidas em um diálogo intertranscultural. As culturas dialogam pela mundialização, permitindo-nos visualizar o mundo pela percepção do(s) outro(s). 
Para além dos universos econômicos e capitalistas, a compreensão do outro promove a solidariedade intelectual e moral, o respeito mútuo entre os povos. Por isso

Dada a importância da educação para a compreensão, em todos os níveis educativos e em todas as idades, o desenvolvimento da compreensão necessita de reforma planetária das mentalidades, esta deve ser a tarefa da educação do futuro (MORIN, 2011b, p.91).

A educação, por sua vez, não se encerra no ambiente escolar, porém é a escola um dos espaços de aprendizagem, com agentes educadores abrangendo desde os profissionais administrativos até o quadro de magistério da instituição. Há outros sujeitos que educam pelas relações e se encontram em outros espaços e tempos além dos escolares. Educar integralmente também pressupõe a autoética, compreensão individual e do outro permeadas pela solidariedade. Para Morin (2017) a compreensão deve ser ensinada desde os primeiros anos de escolarização e pressupõe a reforma do pensamento.

Urge a importância de uma ação coesa, coerente com as necessidades de um orbe que clama por socorro. Defendemos uma Educação Integral para além dos espaços escolares, mas que, neles, ganhem sentidos. Uma educação compartilhada entre os membros da sociedade planetária, em busca desta consciência mútua de compreensão, respeito e ética pela humanidade do eu e do outro.

Quando retomamos a pergunta inicial deste trabalho, "Por que educar integralmente?", encontramos a seguinte resposta: as justificativas foram construídas ao longo da história. A educação não tem início na escola e tampouco se finda nela. É um processo contínuo, mutável e incerto, mas depende da ética, esperança e compreensão de todos para consolidar a reforma tão necessária para a sociedade-mundo. Cabe a nós concretizarmos a Educação Integral a partir dos pilares democráticos estabelecidos em comunidade e sociedade em prol da formação do Homo Complexus. 


\section{CONCLUSÃO}

Ao final dos nossos estudos, percebemos que não há como desenvolver qualquer assunto sobre a Educação Integral sem considerar os trabalhos de Edgar Morin, bem como ao abordar a Teoria da Complexidade na educação há aproximações entre ela e a concepção de Educação Integral.

Para nós, o desafio de agora em diante é potencializar cada vez mais esse entendimento para colocarmos em prática o Pensamento Complexo proposto por Edgar Morin. Educar integralmente o Homo Complexus em uma perspectiva integral, integrada e integradora das capacidades e potencialidades humanas, dos saberes e conhecimentos historicamente produzidos, das ligações físicas, biológicas e planetárias, das diferentes culturas e humanidades, das múltiplas organizações sociais e relações entre os indivíduos. O simples e o global se interdependem, a complexidade se faz presente tanto no uno como no múltiplo, pois somos a parte do todo assim como o todo está dentro de nós.

\section{REFERÊNCIAS}

ARROYO, Miguel Gonzáles. O direito a tempos-espaços a um justo digno viver. In: MOLL, Jaqueline et al (Org.). Caminhos da Educação Integral no Brasil: direito a outros tempos e espaços educativos. Porto Alegre: Penso, 2012. Cap. 1. p. 33-45.

BRASIL. Ministério da Educação. Ministério da Educação. Base Nacional Comum Curricular. Brasília: Ministério da Educação, 2018. Disponível em: http://basenacionalcomum.mec.gov.br/wp-content/uploads/2018/02/bncc20dez-site.pdf. Acesso em: 28 fev. 2020.

CAVALIERE, Ana Maria Vilela. Tempo de escola e qualidade na educação pública. Educação e Sociedade, Campinas, v. 28, n. 100, p.1015-1035, out. 2007. Mensal. Disponível em: http://www.scielo.br/pdf/es/v28n100/a1828100. Acesso em: 26 maio 2020.

CAVALIERE, Ana Maria Villela. Educação Integral: uma nova identidade para a escola brasileira?. Educação e Sociedade, Campinas, v. 23, n. 81, p.247-270, dez. 2002. Disponível em: http://www.scielo.br/pdf/es/v23n81/13940.pdf. Acesso em: 10 abr. 2019. 
GADOTTI, Moacir. Educação Integral no Brasil: inovações e processos. São Paulo: Editora e Livraria Instituto Paulo Freire, 2009. Disponível em: http://acervo.paulofreire.org:8080/xmlui/bitstream/handle/7891/3079/FPF_ PTPF_12_076.pdf. Acesso em: 28 fev. 2020.

GUARÁ, Isa Maria F. Rosa. É imprescindível educar integralmente. Cadernos Cenpec | Nova Série, [s.1.], v. 1, n. 2, p.15-24, 1 ago. 2006. Centro de Estudos e Pesquisas em Educação, Cultura e Ação Comunitária (CENPEC). http://dx.doi. org/10.18676/cadernoscenpec.v1i2. Disponível em: http://cadernos.cenpec.org. br/cadernos/index.php/cadernos/issue/view/8. Acesso em: 28 fev. 2020.

MOLL, Jaqueline. A agenda da educação integral: compromissos para sua consolidação como política pública. In: MOLL, Jaqueline et al (Org.). Caminhos da Educação Integral no Brasil: direito a outros tempos e espaços educativos. Porto Alegre: Penso, 2012. Cap. 8. p. 129-146.

MOLL, Jaqueline. Educação integral: texto referência para o debate nacional. Brasília: Ministério da Educação, 2009. Disponível em: http://portal.mec.gov.br/ dmdocuments/cadfinal_educ_integral.pdf. Acesso em: 28 fev. 2020.

MORIN, Edgar. O método 6: ética. 5. ed. Porto Alegre: Sulina, 2017. 224 p. Tradução de: Juremir Machado da Silva.

MORIN, Edgar. Introdução ao pensamento complexo. 5. ed. Porto Alegre: Sulina, 2015. 120 p. Tradução de Eliane Lisboa.

MORIN, Edgar. A via: para o futuro da humanidade. Rio de Janeiro: Bertrand Brasil, 2013. 392 p. Tradução de: Edgard de Assis Carvalho.

MORIN, Edgar. O método 5: a humanidade da humanidade. 5. ed. Porto Alegre: Sulina, 2012. 309 p. Tradução de: Juremir Machado da Silva.

MORIN, Edgar. Rumo ao abismo?: ensaio sobre o destino da humanidade. Rio de Janeiro: Bertrand Brasil, 2011a. 192 p. Tradução de Edgard de Assis Carvalho, Mariza Perassi Bosco. 
MORIN, Edgar. Os sete saberes necessários a educação do futuro. 2. ed. São Paulo: Cortez, 2011b. Tradução de Catarina Eleonora F. da Silva e Jeanne Sawaya; revisão técnica de Edgard de Assis Carvalho.

MORIN, Edgar; CIURANA, Emilio-roger; MOTTA, Raúl Domingo. Educar na era planetária: o pensamento complexo como Método de aprendizagem no erro e na incerteza humana. São Paulo: Cortez, 2003. 111 p. Tradução de: Sandra Trabucco Valenzuela.

RAMOSE, Mogobe B.. A filosofia Ubuntu e Ubuntu como filosofia. 1999. Tradução para uso didático por Arnaldo Vasconcellos. Disponível em: https:/ / filosofia-africana.weebly.com/uploads/1/3/2/1/13213792/texto16.pdf. Acesso em: 20 abr. 2020.

SANTOS, Boaventura de Sousa. Um discurso sobre as ciências. 5. ed. São Paulo: Cortez, 2008. 92 p.

\section{Diovane de César Resende Ribeiro}

Mestre pelo Programa de Pós-graduação em Educação da Universidade Federal do Triângulo Mineiro (PPGE-UFTM). Especialista em Educação e escola em tempo integral: desafios e perspectivas pela Faculdade Educacional da Lapa (FAEL). Graduado em Pedagogia pela Universidade de Uberaba (UNIUBE). Servidor público, vínculo efetivo, na Prefeitura Municipal de Uberaba/Secretaria Municipal de Educação. E-mail: diovane.resende@uberabadigital.com.br

\section{Wagner Wey Moreira}

Doutor em Educação pela Universidade Estadual de Campinas (UNICAMP), Professor do Magistério Superior e líder do Núcleo de Estudos e Pesquisas em Corporeidade e Pedagogia do Movimento (NUCORPO), ambos na Universidade Federal do Triângulo Mineiro; Bolsista de Produtividade CNPq - Educação. E-mail: wagner.moreira@uftm.edu.br 